\title{
Nakit Temettü Politikaları ve Sermaye Birikimi: Seçilmiş Piyasalar Geneli İçin Firmalar Bazında Ampirik Bir Analiz *

\author{
Mustafa ÇAYIR ${ }^{1} \quad$ Nasuh Oğuzhan ALTAY ${ }^{2}$
} \\ Özet
}

\begin{abstract}
Bu çalışmada temettü politikalarının firmaların sermaye birikimi üzerindeki etkileri incelenmiştir. Modelde kullanılan veri seti, S\&P 500, FTSE 100, Nikkei 225, CAC 40, SSEC, BOVESPA, NSEI ve BIST 100 endekslerinden seçilen 1117 banka dişı firmanın 2010-2015 dönemi yıllık gözlemlerinden oluşmaktadır. Sistem GMM yöntemiyle tahmin edilen sonuçlara göre, firmaların nakit temettü ödeme eğiliminin artması, sermaye birikimini olumsuz etkilemektedir. Ayrıca, firma bazında hisse senedi fiyatlarındaki artışların sermaye birikimini olumlu etkilediği saptanmıştır. Bu kapsamda, finansal piyasalardaki fiyat hareketlerinin reel ekonomi üzerindeki etkilerinin fiyat hareketleriyle aynı yönde olduğu söylenebilir.
\end{abstract}

Anahtar Kelimeler: Nakit Temettü Politikalarl, Sermaye Birikimi, Sistem GMM

JEL Sinıflandırma Kodlart: G35, O16, C33

\section{Cash Dividend Policies and Capital Accumulation: An Empirical Analysis on Basis of Firms for Selected Markets-Wide}

\begin{abstract}
The effects of dividend policies on capital accumulation have been investigated in this study. The dataset used in the model consists of annual observations between 2010 and 2015 of 1117 non-bank firms selected from S\&P 500, FTSE 100, Nikkei 225, CAC 40, SSEC, BOVESPA, NSEI and BIST 100 indexes. According to the results that are estimated by System in GMM, increases in the tendency of cash dividend payout of the firms affect capital accumulation as negative. Furthermore, on a firm basis, it has been determined that increases in the stock prices have a positive effect on the capital accumulation. Within this framework, it could be said that the effects of the price movements in the financial markets on the real economy are the same direction of the price movements.
\end{abstract}

Keywords: Cash Dividend Policies, Capital Accumulation, System in GMM

JEL Classification Codes: G35, O16, C33

\footnotetext{
*Bu çalışma Dr. Mustafa ÇAYIR'ın “Sermaye Birikimi ve Temettü Politikaları: Gelişmiş ve Gelişmekte Olan Ülkeler İ I̧in Karılaştırmalı Bir Analiz" başlıklı doktora tezinden türetilmiştir.

${ }^{1}$ Dr. Öğr. Üyesi, Artvin Çoruh Üniversitesi Uygulamalı Bilimler Yüksekokulu, Bankacılık ve Finans Bölümü, Bankacılık ve Finans Anabilim Dalı, mustafacayir@artvin.edu.tr 2 Prof. Dr., Ege Üniversitesi İktisadi ve İdari Bilimler Fakültesi, İktisat Bölümü, İktisat Tarihi Anabilim Dalı, oguzhan.altay@ege.edu.tr
} 


\section{GİRIŞ}

Hisse senedi piyasalarında pay sahiplerine yönelik yapılacak nakit temettü ödemeleri, doğal olarak, firmalardan nakit kaynak çıkışına neden olmaktadır. Kaynak çıkışı, özellikle borçlanma imkânı sınırlı olan firmaların finansman kabiliyetini düşürmektedir. Firmaların finansman kabiliyetindeki azalma da, ilgili firmaların yatırımlarının ertelenmesine ya da tamamen iptal edilmesine neden olabilmektedir (Fazzari vd., 1988: 183-184). Diğer yandan, borçlanma kabiliyeti olsa bile, firmaların yatırımlarını öz kaynaklarının bir kalemi olan kârlardan finanse etmesiyle, borçlanarak finanse etmesi arasında önemli farklar olabilmektedir.

Firma yatırımlarının, öz kaynaklar yerine yabancı kaynaklardan finanse edilmesi, ilgili firmaların sermaye yapısını değiştirmektedir. Sermaye yapısının yabancı kaynak lehine değişmesi de, değişimin boyutu ve borçlanma maliyeti ile öz sermaye maliyeti arasındaki fark ölçüsünde, ağırlıklı ortalama sermaye maliyetini hareket ettirmektir. Borçlanma maliyeti ile öz sermaye maliyeti arasındaki fark, ekonomiden ekonomiye değişiklik arz etmesine rağmen, istisnai bir durum olmadıkça pozitif olmaktadır. Diğer bir anlatımla borçlanma maliyeti, istisnai bir durum olmadıkça, öz sermaye maliyetinden yüksek olmaktadır. Buradan hareketle, sermaye yapısının yabancı kaynak lehine değişmesi ağırlıklı ortalama sermaye maliyetini arttırmaktadır.

Herhangi bir firma yatırım projesini hayata geçirme kararı alırken, ilgili yatırımın beklenen getiri oranı ile ağırlıklı ortalama sermaye maliyetini karşılaştırmaktadır. Yatırımın beklenen getiri oranının, ağırlıklı ortalama sermaye maliyetinden yüksek olması durumunda, firmanın kararı yatırımın hayata geçirilmesi yönünde olacaktır. Dolayısıyla, firmaların ağırlıklı ortalama sermaye maliyetlerinin artması, firmaların yatırım yapmasını oldukça zorlaştırmakta ve firmaların yatırım talebini düşürmektedir.

Yukarıdaki açıklamaların ışığı altında nakit temettü ödemelerinin, firmaların, finansman kabiliyeti ya da ağırlıklı ortalama sermaye maliyeti üzerinden, 
yatırım talebini veya sermaye birikimini etkileyebileceği söylenebilir. $\mathrm{Bu}$ kapsamda çalışmanın temel amacı, firmaların uyguladığı nakit temettü politikalarının ve finansman kabiliyetinin sermaye birikimi üzerinde etkili olup olmadığını tespit edebilmektir. Ayrıca çalışma, firmaların hisse senedi piyasalarında meydana gelen fiyat hareketlerinin sermaye birikimi üzerinde etkili olup olmadığını ve dolayısıyla, fiyatların bilgi içeriği olup olmadığını ortaya koymayı hedeflemektedir. Buradan hareketle, etkin piyasa hipotezinin ${ }^{3}$ geçerli olup olmadığını test etmek de çalışmanın amaçları arasındadır.

\section{LITERATÜR ÖZETİ}

Literatürde temettü politikalarının çeşitli değişkenler üzerindeki etkisine ve temettü politikalarının belirleyicilerine ilişkin birçok akademik çalışma yer almaktadır. Ancak, çok sayıda çalışma bulunmasına rağmen firmaların uyguladığı temettü politikaları ve bu politikaların etkileri konusunda literatürde herhangi bir uzlaşma yoktur. Bu nedenle, temettü politikaları ve bu politikaların çeşitli değişkenler üzerindeki etkileri gizemini korumaktadır. Aşağıda, literatürde yer alan bazı çalışmalara ve ilgili çalışmalarda elde edilen bulgulara değinilmektir.

ABD'de finansal darboğaz altında olmanın firmaların yatırımlarına etkisini araştıran Fazzari vd. (1988) makalesinde, finansal faktörlerin yatırımlar üzerinde etkili olduğu sonucuna varılmıştır. Makalede, ayrıca, temettü ödemelerinden çok, nakit akımlarında meydana gelen dalgalanmaların yatırımlar üzerinde etkili olduğu saptanmıştır.

ABD'de temettü politikalarının ve firmaların likidite darlığı içerisinde olmasının yatırımlar üzerindeki etkisini ele alan Elston (1996) çalışmasında, firmaların likit varlık darlığı çekmesinin yatırım davranışları üzerinde önemli

\footnotetext{
${ }^{3}$ Etkin Piyasa Hipotezi (The Efficient Market Hypothesis): fiyatların bütün bilgileri içerdiği ve eksiksiz işleyen bir piyasa hipotezidir. Eugene F. Fama tarafından literatüre kazandırılan Etkin Piyasa Hipotezi ile ilgili ayrıntılı bilgi için; Fama (1970).
} 
bir etkisinin olduğu, temettü politikalarının ise, yatırımlar üzerinde kayda değer bir etkisinin olmadığı sonucuna ulaşılmıştır.

Birleşik Krallık'taki firmaları ele alarak Finansman Hiyerarşisi Teorisi'ni ${ }^{4}$ test eden Adedeji (1998)'de, temettü ödeme oranıyla yatırımlar arasında ters yönde, temettü ödeme oranıyla kaldıraç oranı arasında ise aynı yönde bir ilişkinin olduğu saptanmıştır. Ayrıca çalışmada, Tobin'in q değerinin, firma büyüklüğünün ve kaldıraç oranının yatırımlar üzerinde anlamlı bir etkisinin olmadığı sonucuna ulaşılmıştır.

Temettü politikalarının AR\&GE harcamalarına ve sermaye birikimine etkilerini inceleyen Gugler (2003), temettü ödemelerinin sermaye birikimini ve AR\&GE harcamalarını negatif etkilediğini, ancak bu etkinin sermaye birikimi için anlamlı, AR\&GE harcamaları için ise, anlamsız olduğunu tespit etmiştir.

Finansal kısıt altında olan ve olmayan firmaların nakit akımlarının ve temettü ödemelerinin yatırımlar üzerindeki etkisini ele alan Moyen (2004), finansal kısıt altında olmayan firmaların temettü ödemeleriyle yatırımları arasında pozitif, finansal kısıt altında olan firmaların temettü ödemeleriyle yatırımları arasında da negatif ilişki olduğunu saptamıştır. Ayrıca ilgili makalede, yatırımların nakit akımlarında meydana gelen dalgalanmalara duyarlılığının, yeni kurulmuş olan firmalarda, köklü firmalara kıyasla, daha yüksek olduğu belirtilmiştir.

Temettü politikalarıyla yatırım fırsatları arasındaki ilişkiyi mercek altına alan Abor ve Bokpin (2010) çalışmasına göre, yatırım firsatlarıyla temettü ödemeleri arasında negatif bir ilişki bulunmaktadır.

Malezya'da sanayi sektöründe faaliyet gösteren firmaların temettü ödemeleriyle yatırım fırsatları arasındaki ilişkinin çalışıldığı Ardestani vd. (2013) makalesinde, yatırım projeleri ile temettü ödemeleri arasında negatif ilişki olduğu saptanmıştır.

\footnotetext{
${ }^{4}$ Finansman Hiyerarşisi Teorisi (Pecking Order Theory): ayrıntılı bilgi için; Donaldson (1961) ve Myers (1984).
} 
Gana borsasında işlem gören firmaların üzerinden Finansman Hiyerarşisi Teorisi'nin test edildiği Fumey ve Doku (2013) çalışmasında elde edilen bulgulara göre, finansal kaldıraç oranıyla temettü ödeme eğilimi arasında aynı yönde bir ilişki varken, finansal kaldıraç oranıyla yatırımlar arasında ve temettü ödeme eğilimiyle yatırımlar arasında anlamlı bir ilişki bulunmamaktadır.

Finansal kısıt altında olan ve olmayan firmaların nakit akımları ile yatırımları arasındaki iliş̧inin irdelendiği Moyen ve Platikanov (2013) makalesinde, finansal kısıt altında olmayan firmalarda nakit akımı yatırımlar üzerinde kayda değer bir etkiye sahip değilken, finansal kısıt altıdaki firmalarda nakit akımının yatırımları olumlu etkilediği sonucuna varılmıştır.

Yukarıdaki çalışmalardan farklı olarak, bu çalışma, ampirik analizin uygulandığı veri setinin kapsamı ve alanı bakımından, literatürdeki diğer çalışmalardan ayrışmaktadır. Ayrıca çalışmada açıklanan değişken olarak, literatürdeki benzerlerinden farklı bir şekilde, yatırım harcamalarının toplam sermayeye oranı değil, toplam sermayedeki değişim alınmıştır. Diğer yandan literatürdeki çalışmalar, genellikle, kullandıkları finansal kısıt endeksine göre, veri setini, "finansal kisit altında olan" ve "finansal kısit altında olmayan" şeklinde bölerek ele alırken, bu çalışmada böyle bir ayrıma gidilmemiştir. Çalışmada finansal kısıt endeks değerleri, finansal kısıtlı1ık düzeyini gösteren bir değişken olarak kullanılmıştır. Ek olarak, yine literatürdeki benzerlerinden farklı şekilde, bu çalışmada, hisse senedi fiyat hareketlerinin ilgili firmaların sermaye birikimi üzerinde etkili olup olmadığı da ele alınmaktadır. Dolayısıyla, önceki cümlelerde belirtilen nedenlerle, bu çalışmanın ilgili literatüre katk1 sağlaması hedeflenmektedir.

\section{VERİ SETI VE MODEL}

Modelin kurulum sürecinde, öncelikle, teorik olarak sermaye birikimini etkileyeceğini düşündüğümüz değişkenler modele dahil edilmiştir. Ardından literatürdeki benzer çalışmalarda yaygın olarak kullanılan değişkenler modele dahil edilmiştir. Bu çerçevede, kurulan ekonometrik model aşağıdaki gibidir. 


$$
\begin{aligned}
& \left(\frac{\Delta(\text { Serm.Stoku })}{\text { Serm.Stoku }}\right)_{i, t} \\
& =\text { Sabit }+\beta_{1}\left(\frac{\text { Piy.De } \breve{\mathrm{g}} .}{\text { Def.De } \breve{\mathrm{g}} .}\right)_{i, t}+\beta_{2}\left(\frac{\text { Nakit Akım }}{\text { Serm. Stoku }}\right)_{i, t-1} \\
& +\beta_{3}\left(\frac{\text { Satışlar }}{\text { Serm.Stoku }}\right)_{i, t-1}+\beta_{4}(\text { Cleary, 1999 })_{i, t} \\
& +\beta_{5}\left(\frac{\Delta(\text { His.Fyt. })}{\text { His.Fyt. }}\right)_{i, t}+\beta_{6}\left(\frac{\text { Dă̆ } \text { ltılan Kârlar }}{\text { Toplam Kârlar }}\right)_{i, t} \\
& +\beta_{7}(2010 \text { Kukla })+\beta_{8}(2011 \text { Kukla })+\beta_{9}(2012 \text { Kukla }) \\
& +\beta_{10}(2013 \text { Kukla })+\beta_{11}(2014 \text { Kukla }) \\
& +\beta_{12}(2015 \text { Kukla })+\beta_{13}(\text { ABD Kukla }) \\
& +\beta_{14}(\text { Birleşik Krallık Kukla })+\beta_{15}(\text { Japonya Kukla }) \\
& +\beta_{16}(\text { Fransa Kukla })+\beta_{17}(\text { Çin Kukla }) \\
& +\beta_{18}(\text { Brezilya Kukla })+\beta_{19}(\text { Hindistan Kukla }) \\
& +\beta_{20}(\text { Türkiye Kukla })+\varepsilon_{i, t}
\end{aligned}
$$

Çalışmada kullanılan verilerin tamamı Amerikan Doları cinsinden edinilmiştir. Bu durum, oran şeklinde olan değişkenler için bir değişiklik arz etmemekle birlikte, oran olarak ifade edilmeyen değişkenlerde, piyasalar arasında para birimi farklılıklarından kaynaklanabilecek olan riskleri bertaraf etmektedir.

$(\Delta($ Serm. Stoku $) /$ Serm. Stoku $)$; sonuç tablolarında " $\delta \mathrm{K} / \mathrm{K}$ " ifadesiyle simgelenen değişken, firmaların $\mathrm{t}$ dönemindeki toplam sermayesiyle, $\mathrm{t}-1$ dönemindeki toplam sermayesinin logaritmik farkıdır. Ayrıca modelde "Sabit" ifadesiyle belirtilen değişken, sonuç tablolarında "C" harfiyle belirtilmekte ve modelin sabit değişkenini göstermektedir.

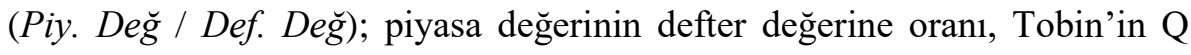
oranına benzer şekilde, firmaların entelektüel sermayelerinin toplam sermayeleri içerisindeki payını ölçmekte kullanılmaktadır (Dzinkowski, 2000: 3-4 aktaran Lin, 2007: 99). Öte yandan, sonuç tablolarında "PD/DD" şeklinde 
gösterilen piyasa değeri defter değeri oranının artması, firmaların yeni hisse senedi ihraç etmesi ya da firma bünyesinde mevcut olan hisse senetlerini piyasada satması halinde elde edilecek finansman miktarını arttırmaktadır. O halde, yine Tobin'in Q oranına benzer bir şekilde, piyasa değeri defter değeri oranı arttıkça firmaların finansman bulma kabiliyetinin de arttığı söylenebilir. Ayrıca, Tobin'in Q oranı ve piyasa değeri defter değeri oranı değişkenlerinin birbiriyle yakın ilişkili olması sebebiyle, ilgili değişkenler, literatürdeki birçok çalışmada firmaların yatırım firsatlarının göstergesi olarak da kullanılmaktadır ${ }^{5}$. Son olarak, PD/DD oranındaki artışların sermaye birikimini olumlu etkilemesi, yani $\beta_{1}$ katsayısının pozitif olması beklenmektedir.

(Nakit Akımı / Serm. Stoku); nakit akımının toplam sermayeye oranı, bu konudaki literatürün başta gelen çalışmalarından biri olan Fazzari vd. (1988)'de, sermaye birikimi üzerindeki etkisi bakımından önem seviyesi en yüksek olan değişkenlerden biri olarak gösterilmektedir. Teorik olarak nakit akımıyla sermaye birikimi arasında aynı yönde bir ilişkinin olması ve $\beta_{2}$ katsayısının pozitif olması beklenmektedir. Diğer yandan, nakit akımı sermaye birikimini uyarıcı niteliğindedir. Dolayısıyla, toplam sermayenin nakit akımındaki değişime hemen cevap vermesinden çok, en azından bir dönem sonra cevap vermesi beklenir. Ayrıca, dikkat edilecek olursa, nakit akımının toplam sermayeye oranı içsellik (endogeneity) bakımından yüksek risk taşımaktadır. Sermaye birikiminin nakit akımındaki değişimlere hemen cevap vermesinin beklenmemesi ve bu değişkenin içsellik bakımından yüksek risk içermesi nedeniyle, modelde ilgili değişkenin bir gecikmeli değerleri kullanılmıştır. Nakit akımının toplam sermayeye oranı sonuç tablolarında " $\mathrm{CF} / \mathrm{K}$ " ifadesiyle belirtilmiştir.

(Satışlar / Serm. Stoku); satış hasılatının toplam sermayeye oranı olan değişken, sonuç tablolarında " $\mathrm{S} / \mathrm{K}$ " ifadesiyle gösterilmektedir. Harrod Domar

\footnotetext{
${ }^{5}$ Konuyla ilgili daha ayrıntılı bilgi için; Aivazian vd. (2003) ve Abor ve Bokpin (2010).
} 
Birikim Modeli'ne ${ }^{6}$ göre talep ile sermaye birikimi arasında aynı yönde sıkı bir ilişki bulunmaktadır ve dolayısıyla, teorik olarak $\beta_{3}$ katsayısının pozitif olması beklenmektedir. Diğer yandan, tıpkı CF/K'da olduğu gibi, sermaye birikiminin satış hasılatındaki değişimlere hemen cevap vermesinden çok, bir dönem sonra cevap vermesi beklenmektedir. Ayrıca, yine $\mathrm{CF} / \mathrm{K}$ 'ya benzer şekilde, satış hasılatının toplam sermayeye oranı için de ciddi düzeyde içsellik riski bulunmaktadır. $\mathrm{Bu}$ nedenlerle, modelde satış hasılatının toplam sermayeye oranının gecikmeli değerleri kullanılmıştır.

(Cleary, 1999); Sean Cleary'nin 1999 yılında literatüre kazandırdığı finansal kısıt endeksidir. Cleary finansal kısıt endeks değerleri ${ }^{7}$ arttıkça firmaların finansal kısıtlılığı azalmaktadır. Dolayısıyla $\beta_{4}$ katsayısının pozitif olması, yani Cleary finansal kısıt endeks değerleriyle sermaye birikimi arasında aynı yönde bir iliş̧inin olması beklenir. Cleary finansal kısıt endeksi sonuç tablolarında "CLRY" şeklinde ifade edilmektedir.

( $\Delta$ (His. Fyt.) / His. Fyt.); 1 adet hisse senedinin t dönemindeki değeriyle t-1 dönemindeki değerinin logaritmik farklarından oluşmaktadır. Firmaların piyasa değerindeki oransal değişimler, fiyatların bütün bilgileri içerdiği ve piyasanın sağlıklı işlediği, yani etkin piyasa hipotezinin geçerli olduğu varsayımı altında, ilgili firmaların piyasadaki itibarlarının bir göstergesi niteliğindedir. Bir firmanın piyasadaki itibarı ise, ilgili firmanın kredibilitesini arttırmaktadır. ${ }^{8}$ Dolayısıyla, ilgili değişkeninin katsayısı olan $\beta_{5}$ 'in pozitif olmasını öngörmekteyiz. Ayrıca, itibar değerindeki değişim, sonuç tablolarında " $\delta \mathrm{P} / \mathrm{P}$ " şeklinde ifade edilmektedir.

(Dağıtılan Kârlar / Toplam Kârlar); nakit olarak dağıtılan kârların, toplam kârlara oranıdır. İlgili değişken modelde "nakit temettü politika değişkeni" olarak kullanılmıştır. Nakit temettü ödemeleri firmalardan kaynak çıkışına

${ }^{6}$ Ayrıntılı bilgi için bakınız: Harrod (1939) ve Domar (1946).

${ }^{7}$ Cleary finansal kısıt endeks değerlerinin hesaplanışı çalışmanın "Ekler" bölümünde yer almaktadır. Ayrıntılı bilgi için; Cleary (1999).

8 Bu konuda daha ayrıntılı bilgi için bakınız: Öztin Akgüç, Kredi Taleplerinin Değerlendirilmesi, 10. Baskı, Arayış Basım ve Yayıncılık, İstanbul: 2014. 
neden olmaktadır. Kullanabileceği likit ve hazır kaynakları azalan firmalar için ise yatırım yapmak daha zor bir karar haline gelmektedir. Bu nedenle, nakit temettü ödeme oranının ya da nakit temettü ödeme eğilimi olarak da adlandırılan değişkenin sermaye birikimi üzerinde negatif yönde etkili olmasını beklemekteyiz. Yani, teorik olarak $\beta_{6}$ katsayısının işaretinin negatif olması beklenmektedir. Son olarak, nakit temettü ödeme oranı sonuç tablolarında "NTMO" ifadesiyle simgelenmektedir.

(2010 Kukla), (2011 Kukla), (2012 Kukla), (2013 Kukla), (2014 Kukla) ve (2015 Kukla); çalışmada kullanılan veri setinin zaman boyutu yıllık gözlemlerden ve altı dönemden oluşmaktadır. Çalışmamızda incelenen yıllar 2010 - 2015 dönemini kapsamaktadır. Her bir yılın kendi içerisinde faklı gündemleri, yaşanan ekonomik ve politik olayları mevcuttur. Bu nedenle, sermaye birikimi yıllar arasında farklılaşabilmektedir. Dolayısıyla, ilgili kukla değişkenler bu farklılaşmaları ölçebilmek maksadıyla kullanılmıştır. Örneğin, 2013 y1lı için kullanılan kukla değişken, 2013 y1lı gözlemleri için "1”, diğer yılların gözlemleri için "0" değerlerinden oluşmaktadır. Yıllar için oluşturulan kukla değişkenler sonuç tablolarında, 2010 y1lı için "t-0", 2011 y1lı için "t-1", 2012 y1lı için "t-2", 2013 y1l için "t-3", 2014 y1lı için “t-4" ve son olarak, 2015 y1lı için "t-5" şeklinde simgelenmektedir.

(ABD Kukla), (Birleşik Krallık Kukla), (Japonya Kukla), (Fransa Kukla), (Çin Kukla), (Brezilya Kukla), (Hindistan Kukla), ve (Türkiye Kukla); çalışmanın analiz kısmında kullanılan firmalar, 8 farklı ülkenin gösterge endekslerinde işlem gören firmaların arasından seçilmiştir. Her piyasanın ve ülkenin kendine özgü dinamikleri vardır. Bu nedenle firmaların sermaye birikimi, çeşitli değişkenlerden etkilenmesinin yanı sıra, içinde bulundukları piyasadan ve ülkeden soyutlanamaz. Dolayısıyla, ilgili kukla değişkenler farklı piyasa dinamiklerinin sermaye birikimi üzerinde etkili olup olmadığını ortaya koymak amaciyla modele dahil edilmiştir. İlgili kukla değişkenler sonuç tablolarında, sirasiyla, “d-US”, “d-GB”, “d-JP”, “d-FR”, “d-CN”, “d-BR”, “dIN" ve "d-TR" şeklinde ifade edilmektedir. Son olarak, örneğin, d-CN kukla 
değişkeni, Çin firmaları için " 1 ”, diğer ülkelerin firmaları için " 0 " değerlerinden oluşmaktadır.

Çalışmada 2010 - 2015 dönemi ele alınmakta ve veri seti yıllık gözlemlerden oluşmaktadır. Dolayısıyla, veri setinin zaman boyutu $(\mathrm{T}=6)$ altıdır. Çalışmada kullanılan veri setinin kesit boyutu da, 2010 - 2015 döneminin herhangi bir zaman diliminde, ABD S\&P 500, Birleşik Krallık FTSE 100, Japonya Nikkei 225, Fransa CAC 40, Çin SSEC, Brezilya Bovespa, Hindistan NSEI ve Türkiye BIST 100 endekslerinde işlem görmüş banka dışı ve verileri mevcut olan firmalardan oluşmaktadır. İlgili ülkelerden ve endekslerden, sirasıyla, ABD S\&P 500 endeksinden 372, Birleşik Krallık FTSE 100 endeksinden 87, Japonya Nikkei 225 endeksinden 184, Fransa CAC 40 endeksinden 40, Çin SSEC endeksinden 272, Brezilya BOVESPA endeksinden 49, Hindistan NSEI endeksinden 51 ve son olarak Türkiye BIST 100 endeksinden 62 adet firma örnek hacmine dahil edilmiştir. Dolayısıyla, veri setinin yatay kesiti toplamda 8 farklı piyasadan seçilen 1117 firmadan $(\mathrm{N}=$ 1117) oluşmaktadır. Son olarak, çalışmada kullanılan verilerin tamamı Thomson Reuters veri tabanından elde edilmiştir.

\section{EKONOMETRİK YÖNTEM VE AMPİRIKK BULGULAR}

Öncelikle analizde kullanılan veri seti dikkate alındığında, bazı firmalar için bazı gözlemlerin eksik olduğunu belirtmeliyiz. Bu durum elimizdeki veri setinin dengesiz (unbalanced) panel olduğunu göstermektedir. Dengesiz panel veri setlerinde birinci farkların alınması gözlem kayıplarını arttırmaktadır. Gözlem kayıplarının en aza indirilebilmesi için düzeyde olan denklemler için farkları alınmış değişkenlerin gecikmeli değerleri, farkları alınmış denklemler için de, düzeydeki değişkenlerin gecikmeli değerleri alınarak, bu iki denklem sistemi birlikte tahmin edilmektedir. $\mathrm{Bu}$ tahmin yöntemi Sistem Genelleştirilmiş Momentler Metodu (Sistem GMM) olarak adlandırılmaktadır. ${ }^{9}$ Ayrıca, ekonometrik analizde kullanılan veri setinin kesit boyutu (1117), zaman

\footnotetext{
${ }^{9}$ Ayrıntılı bilgi için bakınız: Arellano ve Bover (1995) ve Blundell ve Bond (1998).
} 
boyutundan (6) büyüktür ve ekonometrik modelimizde içsel değişkenler yer almaktadır. $\mathrm{Bu}$ nedenle, çalışmanın ekonometrik analizinde Sistem GMM yöntemi kullanılmıştır. Diğer yandan, analiz ${ }^{10}$, Stata 13 programında, Roodman'ın geliştirdiği "xtabond2" komutu kullanılarak hayata geçirilmiştir. ${ }^{11}$ $\mathrm{Bu}$ komut daha fazla tanı testine imkân vermesinin yanı sıra, değişen varyansa ve otokorelasyona dirençli tahminler yapabilmektedir. (Tatoğlu, 2012: 85-96). Son olarak, Stata programında uygulanan analizde, Windmeijer'in 2005 y1lında standart hataların etkin tahmin edilmesine yönelik geliştirdiği Windmeijer düzeltme tekniği kullanılmıştır. ${ }^{12}$

Tablo 1: Özet İstatistiki Bilgiler

\begin{tabular}{|c|c|c|c|c|}
\hline Değişken & Ortalama & Standart Sapma & Minimum & Maksimum \\
\hline $\boldsymbol{\delta K} / \mathbf{K}$ & 0,054 & 0,203 & $-2,207$ & 2,028 \\
\hline $\mathbf{P D / D D}$ & 2,598 & 5,06 & $-326,08$ & 52,497 \\
\hline $\mathbf{C F} / \mathbf{K}(-\mathbf{1})$ & 0,477 & 19,028 & $-0,615$ & 1326,349 \\
\hline S/K (-1) & 1,199 & 0,892 & $-0,451$ & 18,096 \\
\hline $\mathbf{C L R Y}$ & 0,23 & 0,359 & $-1,032$ & 1,563 \\
\hline $\boldsymbol{\delta P / P}$ & 0,03 & 0,311 & $-1,895$ & 1,155 \\
\hline NTMO & 0,551 & 4,295 & $-3,09$ & 270,171 \\
\hline
\end{tabular}

Tabloda değişkenlerin yanındaki "(-1)" ifadesi, ilgili değişkenlerin 1 gecikmeli değerlerinin kullanıldığını göstermektedir.

Yukarıdaki tabloda ABD, Birleşik Krallık, Japonya, Fransa, Çin, Brezilya Hindistan ve Türkiye piyasalarında faaliyet gösteren 1117 banka dışı firmanın verilerinden elde edilen özet istatistiki bilgiler yer almaktadır. Buna göre, 20102015 yılları için, firmalar, toplam sermayelerini her y1l ortalama \% 5,4 arttırırken, kârlarının ortalama \% 55,1'ini nakit temettü olarak dağıtmıştır.

\footnotetext{
10 Çalışma kapsamında yapılan analizde dışa düşen (outlier) gözlemler "bacon" komutuyla tespit edilerek, veri setinden çıkarılmıştır. Konuyla ilgili ayrıntılı bilgi için; Weber (2010).

${ }^{11}$ Ayrıntılı bilgi için; Roodman (2009).

12 Windmeijer 2005 yılında yaptığı çalışmayla iki aşamalı GMM yönteminde standart hataların, özellikle küçük örneklemlerde, asimptotik olarak sapmalı olduğunu göstermiş ve ilgili çalışmada bu probleme çözüm önerisi sunmuştur. Ayrıntılı bilgi için; Windmeijer (2005).
} 
Tablo 2: Korelasyon Matrisi

\begin{tabular}{|c|c|c|c|c|c|c|c|}
\hline & $\boldsymbol{\delta} \mathbf{K} / \mathbf{K}$ & $\mathbf{P D} / \mathbf{D D}$ & $\mathbf{C F} / \mathbf{K}(-\mathbf{)})$ & $\mathbf{S} / \mathbf{K}(-\mathbf{1})$ & $\mathbf{C L R Y}$ & $\boldsymbol{\delta P} / \mathbf{P}$ & $\mathbf{N T M O}$ \\
\hline $\boldsymbol{\delta} \mathbf{K} / \mathbf{K}$ & 1 & & & & & & \\
\hline $\mathbf{P D} / \mathbf{D D}$ & 0,235 & 1 & & & & & \\
\hline $\mathbf{C F} / \mathbf{K}(-\mathbf{1})$ & 0,008 & 0,006 & 1 & & & & \\
\hline S/K (-1) & 0,058 & 0,163 & $-0,024$ & 1 & & & \\
\hline $\mathbf{C L R Y}$ & 0,305 & 0,337 & 0,091 & $-0,292$ & 1 & & \\
\hline $\boldsymbol{\delta} \mathbf{P} / \mathbf{P}$ & 0,062 & 0,168 & $-0,032$ & $-0,047$ & 0,06 & 1 & \\
\hline NTMO & $-0,031$ & $-0,017$ & $-0,027$ & $-0,017$ & $-0,008$ & $-0,013$ & 1 \\
\hline
\end{tabular}

Tabloda değişkenlerin yanındaki “(-1)” ifadesi, ilgili değişkenlerin 1 gecikmeli değerlerinin kullanıldığını göstermektedir.

Yukarıdaki tabloda değişkenlerin korelasyon matrisi yer almaktadır. Yapılan varyans enflasyon faktörü (vif) testinde, test istatistik değerlerinin, bağımsız değişkenler arasındaki çoklu doğrusal bağlantı konusunda, tehdit edici düzeyde yüksek olduğu saptanmıştır. Bu nedenle, ekonometrik analizde, $\delta \mathrm{P} / \mathrm{P}$ ve NTMO değişkenleri normalize edilerek kullanılmıştır. İlgili değişkenler normalize edildikten sonra yapılan varyans enflasyon faktörü testinde ${ }^{13}$, değişkenler arasında çoklu doğrusal bağlantı (multicollinearity) tespit edilmemiştir.

Özet İstatistiki Bilgiler ve Korelasyon Matrisi tablolarıyla çalışmada kullanılan veri setine ilişkin genel bilgiler sunulmuştur. Şimdi, temettü politikalarının sermaye birikimi üzerindeki etkilerini açıklamaya yönelik yapılan ekonometrik uygulamanın sonuçlarına geçelim.

Aşağıdaki tabloda Sistem GMM yöntemiyle yapılan tahmin sonuçlarının yanı sıra, kıyaslama yapılabilmesi amacıyla, sabit etkiler tahmin sonuçları da yer almaktadır.

\footnotetext{
${ }^{13}$ ilgili varyans enflasyon testi çalışmanın "Ekler" bölümünde yer almaktadır.
} 
Tablo 3: Temettü Politikalarının Sermaye Birikimine Etkilerine Yönelik Analiz

\begin{tabular}{|c|c|c|c|}
\hline Değişken & Sabit Etkiler & \multicolumn{2}{|c|}{ Sistem GMM } \\
\hline $\mathbf{C}$ & $-0,207 * * *(0,014)$ & & \\
\hline PD/DD & $-0,004(0,003)$ & \multicolumn{2}{|c|}{$-0,062 * * *(0,017)$} \\
\hline CF/K (-1) & $0,001 \quad(0,001)$ & \multicolumn{2}{|c|}{$0,054 *(0,032)$} \\
\hline S/K (-1) & $0,152 * * *(0,011)$ & \multicolumn{2}{|c|}{$0,157 * * *(0,049)$} \\
\hline CLRY & $0,178 * * *(0,012)$ & \multicolumn{2}{|c|}{$0,411 * * *(0,09)$} \\
\hline$\delta \mathbf{P} / \mathbf{P}$ & $0,028 * * *(0,006)$ & \multicolumn{2}{|c|}{$0,088 * * *(0,031)$} \\
\hline NTMO & $0,001(0,005)$ & \multicolumn{2}{|c|}{$-0,093 * *(0,039)$} \\
\hline \multicolumn{4}{|l|}{ t - 10 ve $d-G B$} \\
\hline$t-11$ & $0,039 * * *(0,006)$ & \multicolumn{2}{|c|}{$-0,155 * *(0,074)$} \\
\hline$t-12$ & $0,023 * * *(0,006)$ & \multicolumn{2}{|c|}{$-0,147 * *(0,075)$} \\
\hline$t-13$ & $0,016 * * *(0,006)$ & \multicolumn{2}{|c|}{$-0,133 *(0,075)$} \\
\hline$t-14$ & $-0,014 * *(0,006)$ & \multicolumn{2}{|c|}{$-0,144 *(0,075)$} \\
\hline$t-15$ & & \multicolumn{2}{|c|}{$-0,121(0,075)$} \\
\hline $\mathbf{d}-\mathbf{U S}$ & & \multicolumn{2}{|c|}{$0,029(0,019)$} \\
\hline $\mathbf{d}-\mathbf{J P}$ & & \multicolumn{2}{|c|}{$-0,004(0,041)$} \\
\hline d-FR & & \multicolumn{2}{|c|}{$0,002(0,031)$} \\
\hline $\mathbf{d}-\mathbf{C N}$ & & \multicolumn{2}{|c|}{$0,079 * * *(0,025)$} \\
\hline $\mathbf{d}-\mathbf{B R}$ & & \multicolumn{2}{|c|}{$-0,015(0,039)$} \\
\hline $\mathbf{d}-\mathbf{I N}$ & & \multicolumn{2}{|c|}{$0,063 * *(0,029)$} \\
\hline d-TR & & \multicolumn{2}{|c|}{$-0,002(0,036)$} \\
\hline & & \multicolumn{2}{|c|}{ Regresyon Tanı Testleri } \\
\hline Test & & Test İstatistik Değeri & Olasılık Değeri \\
\hline Wald Testi & & 288,86 & 0,000 \\
\hline AR (1) & & $-7,76$ & 0,000 \\
\hline AR (2) & & $-0,57$ & 0,57 \\
\hline AR (3) & & $-1,36$ & 0,173 \\
\hline Sargan Testi & & 23,47 & 0,036 \\
\hline Hansen Testi & & 12,18 & 0,513 \\
\hline Veri Seti & Yatay Kesit & $=963-$ Gözlem Sayısı & 3545 \\
\hline
\end{tabular}

Tabloda parantez içerisinde yer alan ifadeler katsayıların standart sapmalarını göstermektedir Katsayıların yanında yer alan “***”, “**” ve “*” ifadeleri ilgili katsayının, sırasıyla \% 1, \% 5 ve \% 10 önem seviyesinde istatistiki olarak anlamlı olduğunu ifade etmektedir. Ayrıca değişkenlere özel yapılan Hansen test sonuçları makalenin Ekler bölümünde sunulmuştur. Diğer yandan, yukarıda sonuçları verilen regresyon tahminlerinde bağımlı değişkenin, firmaların sermaye stokundaki yıllık değişim oranı $(\delta \mathrm{K} / \mathrm{K})$ olduğunu belirtelim. Son olarak, tabloda değişkenlerin yanındaki “(-1)” ifadesi, ilgili değişkenlerin 1 gecikmeli değerlerinin kullanıldığını göstermektedir. 
Piyasa değeri defter değeri oranının artması, firmaların hisse senedi ihraçlarından finansman bulma kapasitesini arttıracağı için, teorik olarak, sermaye birikiminin bu durumdan olumlu etkilenmesi beklenir. Ancak, sonuç tablosunda görüldüğü üzere, PD/DD oranıyla sermaye birikimi arasında ters yönde ve anlamlı bir ilişki tespit edilmiştir. PD/DD oranının artmasıyla birlikte firma yönetiminde etkili olan dominant ortaklar elindeki hisse senetlerinin bir kısmını satarak, elde ettikleri kaynağı daha kârlı ve hızlı gelişen sektörlerde yeni firmalar ya da ortakliklar kurmak amaciyla kullanabilmektedir. Bu durum, dominant ortakların hisse senetlerini sattığı ve ortaklık payını azalttığı firmalara, ilgili ortakların verdiği önemi de azaltabilmektedir. Dolayısıyla, PD/DD oranının yükselmesi, dominant otakların firmadaki ortaklık payını azaltmasına neden olabilmekte ve buna bağlı olarak, sermaye birikimi başta olmak üzere, ilgili firmaların birçok dinamiği bu durumdan olumsuz etkilenebilmektedir.

Firmaların nakit akımlarının toplam sermayesine oranı $(\mathrm{CF} / \mathrm{K}(-1))$ arttıkça izleyen dönemin sermaye birikim hızının anlamlı düzeyde arttı̆̆ tespit edilmiştir. Bu sonuç, teorik beklentilerimize uygun olmakla birlikte, Fazzari vd. (1988), Moyen (2004) ve Moyen ve Platikanov (2013) çalışmaları başta olmak üzere, literatürdeki çalışmaların büyük bir bölümüyle de örtüşmektedir.

Firmaların satış hasılatının toplam sermayeye oranının artması ( $\mathrm{S} / \mathrm{K}(-1))$, ilgili firmaların bir sonraki dönemdeki sermaye birikim oranını arttırmaktadır. Teorik beklentilerimizle örtüşen bu sonuç, literatürdeki birçok çalışmayı da destekler niteliktedir. Bolbol ve Omran (2005) çalışması, nakit akımı konusunda Fazzari vd. (1988) çalışmasına karşıt sonuçlar elde etmesine rağmen, satışlar konusunda elde ettiğimiz sonuçların desteklediği çalışmalara örnek olarak gösterilebilir. Diğer yandan, nakit akımının sermayeye oranı ve satışların sermayeye oranı değişkenleri, Keynesyen değişkenler olmasının yanı sıra, sermaye birikimi üzerindeki etkileri bakımından da birbirine benzeyen değişkenler olarak karşımıza çıkmaktadır. Ancak, istatistiki anlamlılık bakımından, $\mathrm{CF} / \mathrm{K}(-1)$ değişkeninden daha anlamlı olan $\mathrm{S} / \mathrm{K}(-1)$ değişkeni, 
sermaye birikiminin duyarlılığı bakımından da $\mathrm{CF} / \mathrm{K}(-1)$ değişkenine karşı üstünlük sağlamaktadır.

Cleary finansal kısıt endeks değerleri arttıkça, ki bu durum finansal kısıtll11k seviyesinin azaldığına işaret etmektedir, firmaların sermaye birikim oranı artmaktadır. Elde edilen bu sonuç teorik beklentilerimizle de uyumludur. Cleary finansal kısıt endeks değerlerinin firmaların sermaye birikimini beklenen yönde ve anlamlı etkiliyor olması, Moyen (2004) ve Moyen ve Platikanov (2013) çalışmalarını destekler nitelikte sonuçlara ulaşıldığını göstermektedir. Ayrıca, makalemizde ulaşılan sonuçlara göre, yine ilgili çalışmalarda belirtildiği gibi, Cleary finansal kısıt endeksinin firmaların finansal kısıtlılığını ölçmekte başarılı ve kullanışlı olduğu söylenebilir.

Firmaların hisse senedi fiyatlarının yükselmesi ya da başka bir ifadeyle piyasa değerinin artması, ilgili firmaların sermaye birikimini anlamlı düzeyde olumlu etkilemektedir. Hatırlanacağı üzere, fiyatların bütün bilgileri içerdiği varsayımı altında, firmaların piyasa değerinin aynı zamanda firmaların piyasadaki saygınlığının ve itibarının göstergesi olduğu varsayılmıştı. Diğer bir ifadeyle, etkin piyasa varsayımı çerçevesinde, firmaların borçlanma kapasitesinin ve genel anlamda kredibilitesinin firmaların piyasadaki itibarından olumlu etkileneceğinden söz edilmişti ve firmaların piyasa değerindeki değişikliklerin sermaye birikimi üzerinde, değişimin yönüyle aynı yönde etkili olacağı belirtilmişti. Dolayısıyla, firmaların piyasa değerindeki değişimin sermaye birikimi üzerindeki etkisini gösteren katsayının işaretinin pozitif olması teorik beklentilerimizle de örtüşmektedir. Bu bulguların 1şı̆̆ altında, fiyatların bilgi içeriği olduğu ve buradan hareketle kredibilite, borçlanma kapasitesi ve maliyeti vs. gibi değişkenlerin piyasa değerinden etkilendiği doğrulanmaktadır.

Firmalardan likit kaynak çıkışına neden olan nakit temettü ödemelerinin sermaye birikimi üzerindeki etkileri için elde edilen sonuçlar teorik beklentilerimizle örtüşmektedir. Bu çerçevede, elde edilen ampirik bulgulara 
göre, firmaların sermaye birikim oranı, nakit temettü ödeme oranının (NTMO) artmasından anlamlı düzeyde negatif etkilenmektedir. İlgili sonuç, literatürdeki genel inanışa uygun bulgular elde eden Adejeji (1998) ve Gugler (2003) ile örtüşürken, genel eğilimin aksine saptamalarda bulunan Ardestani vd. (2013) çalışmasıyla ters düşmektedir.

Son olarak, Tablo 3'te sonuçları sunulan regresyon tanı testlerinden Sargan ve Hansen testleri modelin tahmininde kullanılan araç değişkenlerin uygunluğunu test etmektedir. Buna göre, regresyonda kullanılan araç değişkenler geçerlidir. Öte yandan, AR testleri de modelin yapısını ve doğru kurgulanıp kurgulanmadığını test etmeye yönelik yapılmaktadır. İlgili testlerden elde edilen sonuçlara göre, model doğru bir şekilde kurgulanmıştır ve modelin herhangi bir yapısal sorunu bulunmamaktadır.

\section{SONUÇ VE DEĞERLENDİRME}

Nakit temettü politikalarının sermaye birikimi üzerindeki etkilerini açıklamaya yönelik yapılan analizlerde ulaşılan bulgulara göre, firmaların nakit temettü ödeme oranı arttıkça sermaye birikimi anlamlı düzeyde azalmaktadır. Buna göre, herhangi bir firmanın elde ettiği kârların tamamını dağıtması durumunda, ilgili firmanın sermaye birikimi bu durumdan yaklaşık \% 9,3 oranında negatif etkilenmektedir. Ayrıca buradan hareketle, firmaların finansman kapasiteleri ve finansal kisit altında olup olmamasi sermaye birikimini anlamlı düzeyde etkilemektedir.

Firmaların hisse senedi fiyatlarındaki değişimlerin sermaye birikimi üzerinde anlamlı düzeyde etkili olması, finansal piyasalarda gerçekleşen fiyat hareketlerinin reel piyasalar üzerinde etkili olduğu anlamını taşımaktadır. Buradan hareketle, finansal piyasaların reel ekonomiyi etkilediği söylenebilir. Diğer yandan, firmaların piyasa değerinin sermaye birikimi üzerindeki etkisinin, beklendiği üzere pozitif olması Etkin Piyasa Hipotezini desteklemektedir. Dolayısıyla, bu konuda elde edilen sonuçlar Etkin Piyasa Hipotezi'nin, 
Dokuz Eylül Üniversitesi İktisadi ve İdari Bilimler Fakültesi Dergisi Cilt:33, Sayı:2, Yıl:2018, ss.455-476

davranışsal ekonomi ve finans modelleri tarafından son yıllarda çok eleştirilmesine rağmen, göz ardı edilemeyeceğini göstermektedir. 


\section{KAYNAKÇA}

ABOR, J., BOKPIN, G. A. (2010), "Investment Opportunities, Corporate Finance, and Dividend Payout Policy: Evidence from Emerging Markets", Studies in Economics and Finance, 27 (3), 180 - 194.

ADEDEJI, A. (1998), "Does the Pecking Order Hypothesis Explain the Dividend Payout Ratios of Firms in the UK?", Journal of Business Finance \& Accounting, 25 (9 \& 10), 1127 - 1155.

AIVAZIAN, V., BOOTH, L., CLEARY, S. (2003), "Do Emerging Market Firms Follow Different Dividend Policies from U.S. Firms?", The Journal of Financial Research, 26 (3), 371 - 387.

AKGUC, O. (2014), Kredi Taleplerinin Değerlendirilmesi, Arayış Basım ve Yayınc1lı, İstanbul.

ARDESTANI, H. S., RASID, S. Z. A., BASIRUDDIN, R., MEHRİ, M. (2013), "Dividend Payout Policy, Investment Opportunity Set and Corporate Financing in the Industrial Products Sector of Malaysia", Journal of Applied Finance \& Banking, 3 (1), 123 - 136.

ARELLANO, M., BOVER, O. (1995), "Another Look at the Instrumental Variable Estimation of Error-Components Model", Journal of Econometrics, 68 (1995), $29-51$.

BLUNDELL, B., BOND, S. (1998), "Initial Conditions and Moment Restrictions in Dynamic Panel Data Models", Journal of Econometrics, 87 (1998), $115-143$.

BOLBOL, A. A., OMRAN, M. M. (2005), "Investment and the Stock Market: Evidence from Arab Firm-level Panel Data", Emerging Markets Review, 6 (2005), 85 - 106.

CLEARY, S. (1999), "The Relationship Between Firm Investment and Financial Status", The Journal of Finance, 54 (2), 673 - 692. 
DOMAR, E. D. (1946), "Capital Expansion, Rate of Growth, and Employment”, Econometrica, 14 (2), 137 - 147.

DONALDSON, G. (1961), Corporate Debt Capacity: A Study of Corporate Debt Policy and the Determination of Corporate Debt Capacity, Division of Research, Harvard School of Business Administration, Boston.

DZINKOWSKI, R. (2000), "The Value of Intellectual Capital”, Journal of Business Strategy, 21 (4), 3 - 4.

ELSTON, J. A. (1996), "Dividend Policy and Investment: Theory and Evidence from US Panel Data", Managerial and Decision Economics, 17, 267 275 .

FAMA, F. E. (1970), "Efficient Capital Market: A Review of Theory and Empirical Work", The Journal of Finance, 25 (2), 383 - 417.

FAZZARI, S. M., HUBBARD, R. G., PETERSEN, B. C., BLINDDER, A. S., POTERBA, J. M. (1988), "Financing Constraints and Corporate Investment", Brookings Papers on Economic Activity, 1988 (1), 141 - 206.

FUMEY, A., DOKU, I. (2013), "Dividend Payout Ratio in Ghana: Does the Pecking Order Theory Hold Good?", Journal of Emerging Issues in Economics, Finance and Banking, 2 (2), 616 - 637.

GUGLER, K. (2003), "Corporate Governance, Dividend Payout Policy, and the Interrelation Between Dividends, R\&D, and Capital Investment", Journal of Banking \& Finance, 27, $1297-1321$.

HARROD, R. F. (1939), “An Essay in Dynamic Theory”, The Economic Journal, 49 (193), $14-33$.

LIN, B. W. (2007), "Information Technology Capability and Value Creation: Evidence from the US Banking Industry”, Technology in Society, 29 (2007), 93 $-106$. 
MOYEN, N. (2004), "Investment-Cash Flow Sensitivities: Constrained Versus Unconstrained Firms", The Journal of Finance, 59 (5), 2061 - 2092.

MOYEN, N., PLATIKANOV, S. (2013), "Investment and Financing Constraints", Journal of Accounting and Finance, 13 (3), 29 - 50.

MYERS, S. C. (1984), "Capital Structure Puzzle”, Journal of Finance, 39 (3), $575-592$.

ROODMAN, D. (2009), "How to do xtabond2: An Introduction to Difference and System GMM in Stata", The Stata Journal, 9 (1), 86 - 136.

TAtoglu, F. Y. (2012), Ileri Panel Veri Analizi, Beta Basım Yayın, İstanbul.

WEBER, S. (2010), "bacon: An Effective way to Detect Outliers in Multivariate Data Using Stata (and Mata)", The Stata Journal, 10 (3), 331 338.

WINDMEIJER, F. (2005), "A Finite Sample Correction for the Variance of Linear Efficient two-step GMM Estimators", Journal of Econometrics, 126 (2005), $25-51$. 


\section{EKLER}

\section{Cleary Finansal Kısıt Endeksi}

Cleary $=-0,017 \times$ Cari Oran + 0,0003 $\times$ Gelirin Faizi Karşılama Oranı

$$
\begin{aligned}
& +0,0007 \times \frac{\text { Finansal Esneklik }}{\text { Duran Varlıklar }}+3,904 \times \text { Net Gelir Marjı } \\
& +0,467 \times\left(\frac{\Delta(\text { Satışlar })}{\text { Satışlar }}\right)-0,439 \times \text { Kaldıraç Oranı }
\end{aligned}
$$

Finansal Esneklik

$$
\begin{aligned}
& =\text { Nakit Varlıklar ve Kısa Vadeli Yatırımlar }+0,5 \\
& \times(\text { Envanter })+0,7 \times(\text { Alacaklar })-\text { Kısa Vadeli Borçlar }
\end{aligned}
$$

Varyans Enflasyon Testi

\begin{tabular}{|c|c|c|}
\hline Değişken & VIF & 1/VIF \\
\hline PD/DD & 3,99 & 0,251 \\
\hline S/K (-1) & 3,17 & 0,315 \\
\hline $\boldsymbol{\delta P / P}$ & 3,11 & 0,321 \\
\hline NTMO & 2,15 & 0,466 \\
\hline CLRY & 1,97 & 0,506 \\
\hline CF/K (-1) & 1,01 & 0,986 \\
\hline Ortalama VIF & 2,27 & \\
\hline
\end{tabular}


Değişkenlere Özel Yapılan Hansen Test Sonuçları

\begin{tabular}{|c|c|c|c|}
\hline Açıklama & Test & $\begin{array}{c}\text { Test } \\
\text { İstatistiği }\end{array}$ & $\begin{array}{c}\text { Olasılık } \\
\text { Değeri }\end{array}$ \\
\hline \multirow{2}{*}{ Düzeyde GMM Enstrümanları } & Hansen & 5,14 & 0,273 \\
\hline & Fark & 7,04 & 0,633 \\
\hline \multirow{2}{*}{ Gmm (CF/K, lag (2 5)c) } & Hansen & 4,2 & 0,838 \\
\hline & Fark & 7,98 & 0,157 \\
\hline \multirow{2}{*}{ Gmm (S/K, lag (4 5)c) } & Hansen & 12,03 & 0,283 \\
\hline & Fark & 0,15 & 0,985 \\
\hline \multirow{2}{*}{ Gmm (CLRY, lag (4 4)c) } & Hansen & 8,58 & 0,66 \\
\hline & Fark & 3,6 & 0,165 \\
\hline \multirow{2}{*}{$\operatorname{Gmm}(\delta P / P, \operatorname{lag}(2$ 2)c $)$} & Hansen & 11,41 & 0,409 \\
\hline & Fark & 0,77 & 0,679 \\
\hline \multirow{2}{*}{ Gmm (NTMO, lag (3 4)) } & Hansen & 3,14 & 0,371 \\
\hline & Fark & 9,05 & 0,528 \\
\hline \multirow{2}{*}{$\begin{array}{l}\text { Araç Değişkenler (t-10, t-11, t-12, t-13, t-14, t-15, d- } \\
\text { US, d-UK, d-JP, d-FR, d-CN, d-BR, d-IN, d-TR) }\end{array}$} & Hansen & 3,71 & 0,156 \\
\hline & Fark & 8,47 & 0,67 \\
\hline
\end{tabular}

